\title{
Lunar and diurnal cycles in reproductive physiology and behavior in a natural population of cooperatively breeding fish
}

\author{
J. K. Desjardins ${ }^{1,2}$, J. L. Fitzpatrick ${ }^{3,4}$, K. A. Stiver ${ }^{5,2}$, G. J. Van Der Kraak ${ }^{6}$ \& S. Balshine ${ }^{2}$ \\ 1 Department of Biology, Stanford University, Stanford, CA, USA \\ 2 Animal Behaviour Group, Department of Psychology, Neuroscience \& Behaviour, McMaster University, Hamilton, ON, Canada \\ 3 Centre for Evolutionary Biology, University of Western Australia, Crawley, Australia \\ 4 Department of Biology, McMaster University, Hamilton, ON, Canada \\ 5 Department of Ecology and Evolutionary Biology, Yale University, New Haven, CT, USA \\ 6 College of Biological Sciences, University of Guelph, Guelph, ON, Canada
}

\section{Keywords}

Lake Tanganyika; lunar phase;

Neolamprologus pulcher, sperm swimming

speed; cichlidae; testosterone;

11-ketotestosterone.

\section{Correspondence}

Julie K. Desjardins, Department of Biology,

371 Serra Mall, Stanford University,

Stanford, CA 94305-5020, USA.

Email: desjarjk@stanford.edu

Editor: Jean-Nicolas Volff

Received 30 November 2010; revised 14

March 2011; accepted 18 March 2011

doi:10.1111/j.1469-7998.2011.00814.x

\begin{abstract}
Natural environmental periodicity that occurs on both the small scale like day length, or larger scale like lunar light can provide animals with valuable information about resource availability and predation risk. Such environmental cycles are often linked to the timing of reproduction. Here, using the circulating androgen concentrations, gonadal investment patterns and detailed behavioral observations we show that wild populations of the group-living cichlid, Neolamprologus pulcher from Lake Tanganyika, have marked diurnal differences in behavior and lunar synchronicity in their reproductive physiology and behavior. Female ovarian investment peaked in the first quarter of the lunar cycle. In males, plasma steroid hormone levels and sperm swimming speed were highest at this same lunar stage, supporting the idea that egg laying occurs during this phase and that young will emerge at full moon, perhaps because nocturnal predators can be best detected then. Female subordinate group members' gonadal investment patterns mirrored the lunar pattern observed in dominant female breeders. In contrast, male subordinates did not show a change in gonadal investment or in steroid hormone concentrations across the lunar cycle, suggesting that female subordinates, but not male subordinates, reproduce within the social group. Neolamprologus pulcher demonstrated diurnal cycles in behavior, with higher rates of feeding in the morning. Male and female breeding pairs were strongly size matched potentially as a result of size-assortative mating; also the gonadal investment of male and female mated pairs was strongly correlated indicating within-pair reproductive synchronicity. In general, this study provides evidence for the impact of environmental cues (sunlight and moonlight) on circulating hormones and reproduction in a small tropical freshwater fish.
\end{abstract}

\section{Introduction}

All habitats are subject to both predictable and unpredictable environmental changes that can influence reproductive physiology. Predictable changes such as the difference in daytime light availability and nighttime light availability can be associated with variation in food availability and predation risk. Seasonally breeding animals commonly experience dramatic changes with light or temperature cycles that restrict breeding to only a limited number of months in the year, when conditions for the survival and growth of progeny is optimal (Kramer, 1978; Hau, 2001). In contrast, tropical environments are generally viewed as more stable and breeding often occurs throughout the year (Lowe-
McConnell, 1987; Hau, 2001). Even though light and temperature are more consistent in tropical regions, seasonal events (e.g. rainy seasons, El Nino and La Nina oscillation) can still cause periodic changes in climatic conditions even in the tropics.

In aquatic habitats, reproductive periodicity is often associated with cycles of the sun and moon. Marine species often exhibit lunar or semi-lunar periodicity in breeding (Greeley, Marion \& MacGregor, 1986; Rahman, Morita \& Takemura, 2003; Takemura \& Rahman, 2004), with most reproduction occurring on and/or around the new or full moon (Johannes, 1978). These periods within the lunar cycle are also associated with high survival and active dispersal of both planktonic eggs and young (Schwanck, 1987; Rossiter, 
1991; Neat \& Balshine-Earn, 1999; Watanabe, 2000). In a variety of freshwater and marine teleost species, variation across the lunar cycle has been documented in the hypothalamus-pituitary-gonadal axis, testicular development and in circulating levels of gonadal steroid hormone levels (for review see: Pankhurst \& Carragher, 1991). For example, in several rabbitfish species, males showed dramatic increases in 11-ketotestosterone (11-KT: a fish-specific androgen), testosterone (T) and other reproductive characteristics around the new moon (Hoque, et al., 1999; Rahman, et al., 2003; Takemura \& Rahman, 2004).

In this study, we used a cichlid fish, Neolamprologus pulcher from Lake Tanganyika to investigate reproductive and behavioral patterns in relation to: (1) the lunar cycle; (2) the daily cycle from dawn to dusk. We set out to relate behaviors to reproductive physiology in general and to plasma hormone levels specifically. In addition, we explored the relationship between dominants and subordinates and mated breeding pairs to explore the extent of synchrony in reproductive behavior and physiology. Neolamprologus pulcher is a convenient species to test predictions about periodicity since males and females maintain long-term social bonds and together defend a common breeding territory throughout multiple breeding cycles. The breeding pair is assisted by subordinate conspecifics called helpers (Taborsky $\&$ Limberger, 1981). This unusual breeding system provides an opportunity to track dominant male and female breeders as well as subordinate helpers in the wild (Lake Tanganyika, Africa) through repeated breeding attempts. Since reproduction has been linked to lunar periodicity in a number of other cichlids including many from Lake Tanganyika (Schwanck, 1987; Rossiter, 1991; Neat \& Balshine-Earn, 1999; Watanabe, 2000), our first prediction was that $N$. pulcher reproduction would map onto the lunar cycle. Specifically we predicted that in order to minimize the risk of predation to newly emerged young, spawning would be most common about 1 week before (full moon) to ensure young emerge at the highest availability of night light, as $N$. pulcher are highly visual fish, commonly depredated by a variety of piscivores and are likely to be particularly vulnerable to nocturnal ones. Hence we expected lower spawning rates and higher predation when there is low light available (new moon).

Many animals show diurnal cycles in behavior. It has been suggested that daily foraging patterns result from the benefit of concentrating caloric intake to the time of day when food availability is highest or best balanced against predation risk (Helfman, 1993). The time spent in the search for food is an integral part of the overall activity of the animal, however, in highly social group living species like $N$. pulcher, feeding must be balanced against other social behavioral requirements such as the time needed to attract a mate, defend a territory or maintain dominance rank among group members. Individuals who fail to maintain social contact and other conspecifics with mating partners often risk losing social status and reproductive opportunities (Trivers, 1985). Thus our second prediction was that feeding behavior would occur at the safer time of day and trade-off with other essential social behaviors.
While annual, lunar and daily patterns of behavior are integral to understanding the control and timing of reproduction for a particular species, the interactions between mated individuals can also influence mating success. Synchronicity in male and female reproductive behavior physiology has been shown in a number of avian (Gochfeld, 1980; Findlay \& Cooke, 1982; Murphy \& Schauer, 1996; Smith, 2004) and teleost species (Bye, 1990). It is possible that in tropical freshwater fish, like cichlids, males and females in socially mated pairs use lunar cues to synchronize their reproductive efforts. Our third prediction was that mated pairs of $N$. pulcher would match up on gametic investment patterns and related social behavior.

\section{Methods}

\section{Study species, field site and behavioral measures}

Neolamprologus pulcher live in social groups consisting of a dominant breeding pair and 1-20 subordinate helpers (males and females) that assist in all aspects of care (Taborsky \& Limberger, 1981; Balshine-Earn et al., 1998; Heg, Bachar \& Taborsky, 2005). Care consists of territory/nest defense, territory/nest maintenance and direct brood care (fanning and cleaning of the eggs and larvae). In the field breeders can spawn monthly, dispersal is rare and breeders continue to protect helpers well after sexual maturity (Taborsky, 1984; Stiver, et al., 2004; Stiver, et al., 2007). Males and females are not overtly sexually dimorphic although females tend to be smaller in body size than males (Balshine et al., 2001). As a consequence of dispersal and rapid breeder turnover, helpers are only distantly related to the breeding pair and the youngest brood (Stiver et al., 2005).

Between January 29th and April 29th in 2004 and between February 2nd and April 28th 2005, 88 social groups were studied using SCUBA in Kasakalawe Bay, Lake Tanganyika (Zambia). Each group was monitored one to three times (for an average of $15 \mathrm{~min}$ ) to assess group size and composition; each individual was reliably identified by a combination of underwater size estimates and specific individual markings. Fish were individually marked by fin clipping and injecting non-toxic acrylic paint into scale pockets (Desjardins, et al., 2008a,b). A minimum of 3 days elapsed between capture/marking and behavioral observations. Mean group size in this study was nine individuals; two dominant breeders and seven subordinate helpers (range 6-14 individuals per group).

To investigate diurnal variation in behavior, two focal watches were conducted on each individual, one in the morning (08:00-11:00 h) and the other in the afternoon (14:00-17:00 h, each for 7-10 min). To explore patterns of lunar variation in behavior, fish were followed at four time periods in the lunar cycle corresponding to degree of moonlight. Each focal watch was preceded by a 2 min habituation period, after which fish resume feeding, socializing and actively defending their territory (see Desjardins, et al., $2008 a$ ). To test for diurnal differences in behavior and for 
synchronicity within breeding pairs, only those groups in which we had matched male breeder and female breeder behavioral watches occurring both in the morning and the afternoon on the same day within the same phase of the lunar cycle were included in the analyses. Overall, we had 18 male breeders and their paired 18 female breeders that could be included in the behavioral analysis and 18 matched pairs of male and female breeders for physiological analyses.

Behaviors observed included feeding, territory defense (aggressive behaviors such as ramming, chasing, biting, mouth fighting and defensive posturing toward heterospecifics and neighboring conspecifics), territory maintenance (digging and carrying of substrate), brood chamber visits (where the eggs are laid) and social behaviors (following, soft touching, parallel swimming, tail quivering and submissive postures) (see Sopinka et al., 2009 for a recent ethogram). To score total work effort, we used a composite that was the sum of all behaviors thought to enhance offspring survival; this included defense against heterospecifics and neighboring conspecifics, territory maintenance and visits to the brood chamber. Note, we use visits to the brood chamber as a proxy for direct brood care as in the field it is impossible to observe caring acts such as fanning and egg cleaning and turning that occur deep in the brood chamber. Within-group aggression was defined as a sum of all aggressive behaviors displayed toward one's own group members. Affiliative behavior was defined as the sum of all within-group non-aggressive behaviors (see Sopinka et al 2009). These summed behavioral scores or indices for work effort, within-group aggression and social affiliative behavior have been used previously with this species (Balshine, et al., 2001; Stiver, et al., 2004; Aubin-Horth et al., 2007). To test for behavioral differences between male and female dominant breeders, male and female subordinate helpers, we included all individuals that had been observed at least twice (averaging across observations). With this criterion, we included behavioral observations on 46 male breeders (first quarter $n=8$, full moon $n=12$, third quarter $n=5$, new moon $n=21$ ), 61 female breeders (first quarter $n=7$, full moon $n=14$, third quarter $n=11$, new moon $n=29$ ), 50 male helpers (first quarter $n=5$, full moon $n=12$, third quarter $n=12$, new moon $n=21$ ) and 58 female helpers (first quarter $n=9$, full moon $n=14$, third quarter $n=11$, new moon $n=24$ ).

\section{Blood sampling and hormone assays}

Blood samples were collected during the four phases of the lunar cycle (Fig. 1a). To collect fish we placed a tent net directly over the entire group following the completion of the behavioral observations. We then carefully injected a small volume $(3-7 \mathrm{~mL})$ of an anesthetic [quinaldine; 2methylquinoline; $\left.\mathrm{C}_{6} \mathrm{H}_{4} \mathrm{~N}: \mathrm{C}\left(\mathrm{CH}_{3}\right) \mathrm{CH}: \mathrm{CH}\right)$ ] into the center of the territory while the net was in place and collected the temporarily sedated fish. Fish from each group were placed together in individually marked mesh holding cages $(20 \mathrm{~cm} \times 20 \mathrm{~cm} \times 20 \mathrm{~cm})$ to recover from sedation and were then slowly ( $\sim 20 \mathrm{~min}$ ) brought to the surface.
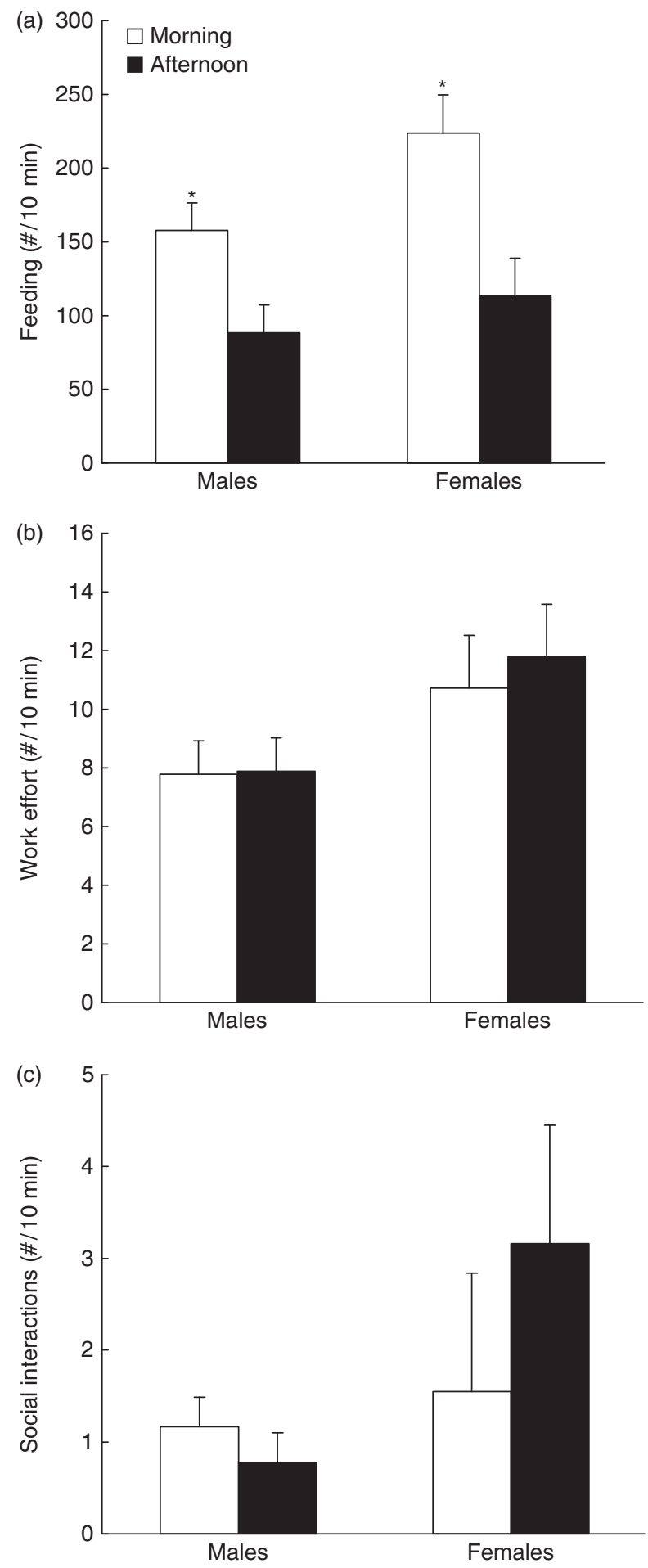

Figure 1 Mean ( $\pm S E$ ) frequency of (a) feeding, (b) work effort and (c) social interactions per 10-min behavioral observation in the morning (08:00 AM-12:00 PM) versus the afternoon (12:01-06:00 PM). Asterisks above bars represent significant difference based on linear contrast analysis, $\alpha=0.05$. These analyses are based on 18 male and 18 female breeding pairs. 
Once at the surface of the water, fish were anesthetized with a lethal dose of benzocaine (ethyl p-aminobenzoate, $1.0 \mu \mathrm{g} /$ $\mathrm{mL}$ ). Fish were measured for standard length (SL) to the nearest millimeter. Body mass was measured to the nearest $0.001 \mathrm{~g}$ and a blood sample was taken by caudal severance. Sex was confirmed by gonadal examination and gonads were weighed to the nearest $0.001 \mathrm{~g}$. Blood was collected and spun at $8000 \mathrm{~g}$ for $10 \mathrm{~min}$ and the separated plasma was removed and stored at $-10^{\circ} \mathrm{C}$ for analysis of $\mathrm{T}$ and $11-\mathrm{KT}$.

We extracted steroids from plasma by shaking the aliquots with $5 \mathrm{~mL}$ of diethyl ether twice. After freezing the aqueous phase in an acetone and dry ice bath, the organic phase was decanted and dried. The dry extracts were resolubilized in assay buffer and frozen at $-20{ }^{\circ} \mathrm{C}$. Extraction losses were independently monitored and recoveries following a double extraction procedure were $88 \pm 4 \%$ (Desjardins, et al., 2006). We used radioimmunoassay (RIA) to measure $\mathrm{T}$ and 11-KT following the techniques to measure steroids from plasma described by McMaster et al. (1995). The reported values are the average concentrations calculated from duplicate aliquots whose values fell within the $5-95 \%$ binding limits of the appropriate standard curve following the linearization with a log-logit transformation. Intra-assay coefficients of variation ranged from 5.8 to $9.3 \%$ for $\mathrm{T}$ and from 4.2 to $8.9 \%$ for $11-\mathrm{KT}$. Inter-assay coefficients of variation did not exceed $15 \%$ in assays for T or 11KT. The assays for T and 11-KT were validated for this species before the experiment and have been reported in Desjardins et al. (2006). Samples with too small a volume to yield a detectable level of hormone were deleted from the dataset. When the blood sample was large enough to reveal a hormone level but a non-detectable hormone level was still observed we estimated the minimum detectable level from the RIA standard curve for this individual to ensure that the means are not artificially inflated by missing data. Therefore, to test for lunar cycles in T, 11-KT we included a total of 24 male breeders of which eight were from the first quarter, six were collected during the full moon, six from the third quarter and four from the new moon phase. We also included a total of 31 female breeders, nine were from the first quarter, seven from the full moon, seven from the third quarter and eight from the new moon. Sixteen male helpers were included, three were from the first quarter, three from the full moon, three from the third quarter and seven from new moon. In addition 21 female helpers were included, five were from the first quarter, five from the full moon, four from the third quarter and seven were collected during the new moon.

\section{Sperm analysis}

Once the testes were weighed, one testis from each male was put on a glass slide, split open with a scalpel and a drop of milt was collected and placed in a $2 \mathrm{~mL}$ microcentrifuge tube. Sperm were activated by adding $0.25 \mathrm{~mL}$ lake water (previously boiled and cooled to lake temperature) and gently shaking the tube for $1-2 \mathrm{~s}$. We then placed the sperm/water mixture in a $1 \mathrm{~mm}$ deep well on a slide, with a cover slip covering half of the depression so that the sperm/water sample could easily be added to the well. This sample was viewed on a Leica DME light microscope (Leica Microsystems Inc., Richmond, VA, USA) mounted with a PixeLINK Megapixel PL-A662 digital video camera (Ottawa, ON, Canada) to record sperm motility. Video recordings began as soon as the water was added to the microcentrifuge tube. Sperm velocity and number of active sperm was measured at $1 \mathrm{~min}$ postactivation. For each male, a mean \pm SE of $18 \pm 0.9$.spermatozoa were measured (range 5-103) for velocity and averaged for each male (for further details see Fitzpatrick, et al., 2006, 2008). For these analyses, only males whose testes could provide a reliable sperm sample were included. Therefore, overall, 24 male breeders were included, eight from the first quarter, six from the full moon phase, six from the third quarter and four from the new moon. Sixteen male helpers were included four from the first quarter, five from the full moon, four from the third quarter and three from the new moon phase.

\section{Statistical analysis}

Statistical analyses were performed using the software JMP 5.1.1 (version 5.1, SAS Institute Inc. 2004, Cary, NC, USA). Data were tested for normality, transformed when necessary and analyzed with parametric tests. Two-tailed tests were used throughout.

To test for the effect of time of day, lunar stage, sex and the interaction between these two fixed factors on hormone levels and on behaviors, we conducted two-way ANOVAs and post hoc linear contrasts analysis (Rosenthal \& Rosnow, 1985). Where post hoc tests were conducted, these were corrected for multiple comparisons to maintain an overall $\alpha$-level equal to 0.05 . We included sex as a fixed factor in our analyses as we have demonstrated previously sex differences in behaviors and physiology (Desjardins, et al., $2008 a, b$ ). Gonado-somatic index (GSI) was calculated as gonad mass/body mass $\times 100$.To test for relationships between breeder males and females in terms of body size (SL and body mass), GSI and behavior, Pearson's correlations and regression analyses were performed.

\section{Ethical note}

The fish were collected over two field seasons that spanned a 15-month period and extreme care was taken not to collect fish from small subpopulations ( $<10$ groups). Neighboring groups were always left intact to minimize the impact of collection, and neighboring fish quickly re-colonized emptied positions and territories, usually within 1-2 days. All research described conformed to the protocols approved by the Animal Research Ethics Board of McMaster University and the Canadian Council for Animal Care guidelines and was conducted with the permission and cooperation of the Zambian Department of Fisheries.

\section{Results}

\section{How does behavior vary across the day and over the lunar cycle?}

Both male and female dominant breeders fed more in the morning than in the afternoon (Fig. 1a; males: $t_{18}=2.46$, 
Table 1 Results of overall model from the two-way ANOVAs testing for lunar effects on behavior in breeding males $(n=46)$, breeding females $(n=61)$, subordinate males $(n=50)$ and subordinate females $(n=58)$

\begin{tabular}{lllll}
\hline Behaviors & Dominant breeding males & Dominant breeding females & Subordinate helper males & Subordinate helper females \\
\hline Feeding & $F_{3,42}=1.04, P=0.38$ & $F_{3,57}=0.31, P=0.81$ & $F_{3,46}=1.55, P=0.21$ & $F_{3,54}=3.12, P=0.03$ \\
Work effort & $F_{3,42}=1.20, P=0.32$ & $F_{3,57}=1.05, P=0.37$ & $F_{3,46}=1.68, P=0.18$ & $F_{3,54}=1.44, P=0.24$ \\
Affiliative behavior & $F_{3,42}=0.09, P=0.96$ & $F_{3,57}=0.01, P=0.99$ & $F_{3,46}=1.380, P=0.26$ & $F_{3,54}=2.88, P=0.04$ \\
\hline
\end{tabular}

$P=0.02$; females: $t_{18}=2.56, P=0.02$ ) but no other single behavior or behavioral index differed in the morning versus the afternoon (work effort: Fig. 1b; males: $t_{18}=0.02$, $P=0.98$; females: $t_{18}=0.48, P=0.64$; social behaviors: Fig. $1 \mathrm{c}$; males: $t_{18}=0.84, P=0.40$; females: $t_{18}=0.91$, $P=0.37$ ). Individual behaviors did not vary significantly across the lunar cycle (see Table 1). The only exception to this was that female subordinate helpers fed more during the third quarter of the moon $\left(\mathrm{F}_{3,54}=3.12, P=0.03\right)$ and socialized most with other group members at the first quarter and the third quarter moon $\left(\mathrm{F}_{3,54}=2.88\right.$, $P=0.04)$.

\section{How did circulating androgens and sperm characteristics vary across the lunar cycle?}

Dominant breeding males showed lunar periodicity in hormone levels with much higher circulating $\mathrm{T}$ and 11-KT in the first quarter moon just before full moon (Fig. 2a, T: $\mathrm{F}_{3,20}=6.63, \quad P=0.002$; Fig. $2 \mathrm{~b}, \quad 11-\mathrm{KT}: \mathrm{F}_{3,20}=3.34$, $P=0.03)$. Dominant breeding females did not show a similar rise in $\mathrm{T}$ or 11-KT levels across the lunar cycle (Fig. $2 \mathrm{a}$ and $\mathrm{b}, \mathrm{T}: \mathrm{F}_{3,27}=0.49, P=0.69: 11-\mathrm{KT}: \mathrm{F}_{3,27}=0.31$, $P=0.81$ ). However, females did show lunar periodicity in gonad investment with highest GSI occurring during this same first quarter moon, the period before full moon (Fig. $\left.2 \mathrm{c}, \mathrm{F}_{3,27}=5.33, P=0.002\right)$. Estrogen levels were not measured in this study because of limited available blood plasma in such small fish, so it remains possible that dominant breeding females have lunar periodicity in estrogen. While gonadal investment $\left(\mathrm{F}_{3,20}=0.58, P=0.63\right)$ and sperm number $\left(\mathrm{F}_{3,20}=0.85, P=0.47\right)$ did not vary across the lunar cycle for dominant breeding males, strong lunar periodicity was observed in sperm swimming speed (mean \pm SE: first quarter: $38.59 \pm 5.53 \mu \mathrm{m} / \mathrm{s}$; full moon: $34.50 \pm 4.52 \mu \mathrm{m} / \mathrm{s}$; third quarter: $14.27 \pm 3.33 \mu \mathrm{m} / \mathrm{s}$; new moon: $15.36 \pm$ $\left.4.03 \mu \mathrm{m} / \mathrm{s} \mathrm{F}_{3,20}=3.23, P=0.03\right)$. The highest sperm swimming speeds were observed at the first quarter and at the full moon.

In subordinate helpers, no lunar periodicity in $\mathrm{T}$ or 11KT levels were observed (T: male helpers: $F_{3,12}=0.15$, $P=0.86$; female helpers: $F_{3,17}=0.31, P=0.82 ; 11-\mathrm{KT}$ : male helpers: $F_{3,12}=3.25, \quad P=0.06$; female helpers: $\left.\mathrm{F}_{3,17}=1.22, P=0.33\right)$. In subordinate male helpers, gonadal investment, sperm number and sperm swimming speeds did not vary across the lunar cycle $\left(\mathrm{GSI}: \mathrm{F}_{3,12}=1.32\right.$, $P=0.27$, sperm number: $\mathrm{F}_{3,12}=1.00, P=0.40$ or sperm velocity: $\left.\mathrm{F}_{3,12}=1.87, P=0.14\right)$. In contrast, subordinate females reproduction showed the same lunar signature observed in dominant females, with highest gonadal invest- ment occurring during the first quarter moon $\left(\mathrm{F}_{3,17}=5.33\right.$, $P=0.002$ )

\section{Are pairs of male and female breeders synchronizing behavior or reproductive physiology?}

Male and female within social pairs were highly correlated in body mass $\left(R^{2}=0.45, \mathrm{~F}_{1,16}=42.20, P<0.0001\right)$, SL $\left(R^{2}=0.24, \mathrm{~F}_{1,16}=16.38, P=0.0002\right)$ and GSI $\left(R^{2}=0.12\right.$, $\left.\mathrm{F}_{1,16}=7.18, P=0.01\right)$. Androgen levels were not correlated within breeding pairs (all $P$ values $>0.23$ ). Feeding rates of dominant male and female breeding pairs were positively correlated $\left(R^{2}=0.18, \mathrm{~F}_{1,16}=12.27, P=0.001\right)$ but interestingly neither the frequency of work effort $\left(\mathrm{R}^{2}=0.02\right.$, $\left.\mathrm{F}_{1,16}=1.33, P=0.25\right)$ nor social behavior were correlated in breeding pairs $\left(\mathrm{R}^{2}=0.10, \mathrm{~F}_{1,16}=6.14, P=0.16\right)$.

\section{Discussion}

A number of patterns suggest that $N$. pulcher spawn just before or around full moon. Dominant female breeders invested dramatically more in gonads during the first quarter moon, and male breeders exhibited a marked increase in androgens and sperm swimming speed during this same first quarter moon period. The high androgen levels in males likely influence sperm quality by triggering the production of hormones that are downstream from $\mathrm{T}$ and 11-KT in the metabolic pathway (specifically 17,20-dihydroxy-4-pregnen3-one, Miura, et al., 2005). Thus, lunar cues appear to influence the hypothalamic-pituitary-gonadal axis in $N$. pulcher breeders.

Why would moonlight be a useful cue for reproductive entrainment? In general, lunar cycles of reproduction are a well-documented feature among marine organisms (Brown, 1957), but are rarely reported in freshwater species (Rossiter, 1991). Neolamprologus pulcher, is a diurnal fish with adhesive eggs and philopatric young. These fish live in an environment with many nocturnal predators. Hence, the link between reproduction and moonlight is more likely a result of the impact of light on nocturnal predator detection. The first quarter moon would represent an ideal time for spawning, as nighttime light would be at its highest (full moon) when the young emerge. Neolamprologus pulcher eggs hatch in 2-3 days and emerge from the attached larval stage of development as free swimming young about 5 days later. Full moon light would provide adults the opportunity to visually detect nocturnal predators entering the brood chamber, and to more effectively protect newly laid eggs or developing embryos. Free-swimming young emerging at the 

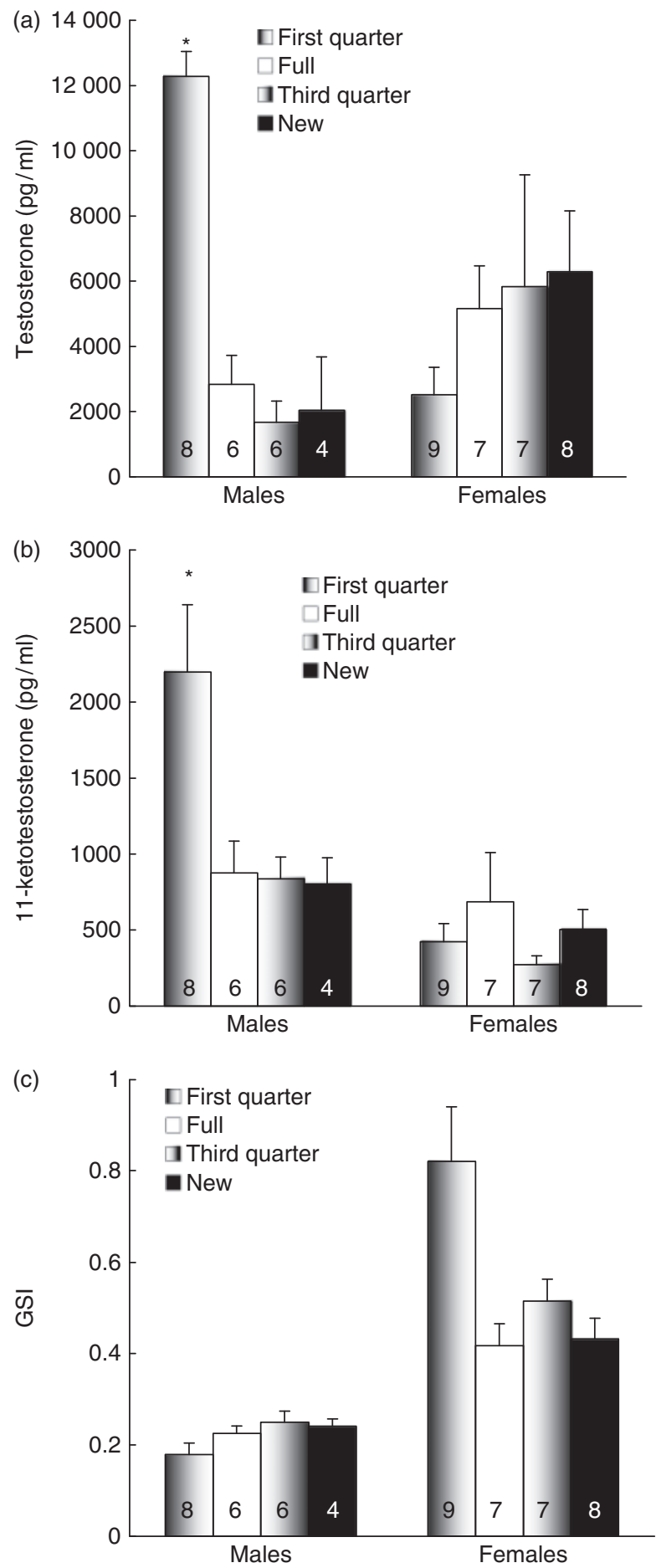

Figure 2 Mean ( $\pm \mathrm{SE}$ ) of (a) testosterone, (b) 11-ketotestosterone and (c) gonado-somatic index across the lunar cycle for dominant males and females. Bar color and shading represent the phase of the lunar cycle in which sampling was conducted. The bar with shading dark to light is the first quarter, the open bar is the full moon, the bar with the shading light to dark is the third quarter and the solid bar represents the new moon. *Significant difference based on linear contrast analysis, $\alpha=0.05$. Sample sizes are indicated within each bar. lightest phase of the lunar cycle (full moon) may have highest survival because nocturnal predators are most conspicuous at full moon.

The lunar cycle link to reproduction in dominant breeder females was mirrored in female subordinate helpers; largest ovaries were found around the first quarter moon. This result suggests that multiple females may be breeding within an $N$. pulcher social group. The phenomenon, of secondary or subordinate females breeding alongside the dominant breeder provides support for female reproductive skew in $N$. pulcher and has been shown to occur in Seychelles warblers Acrocephalus sechellensis (Richardson, et al., 2001) and $N$. pulcher held in the laboratory (Heg et al., 2006) and the field (Stiver, et al., 2009).

The lack of lunar periodicity in male helper androgen levels or in their sperm characteristics suggests that subordinate male helpers do not participate in reproduction, by either sneaking fertilizations from the dominant breeding males (Dierkes, et al., 1998, or mating with female helpers (Fitzpatrick, et al., 2006). The physiological consequences of reproductive suppression in other taxa ranges from reductions in reproductive hormone levels (Faulkes \& Bennett, 2001) to impaired or delayed gonadal development (Faulkes, et al., 1994). Dominant breeder suppression of subordinates may influence hormone levels and sperm quality (Fitzpatrick, et al., 2006, 2008; Desjardins, et al., 2008a).

While individual behavior did not vary consistently over the lunar cycle, there were interesting diurnal patterns in behavior. Both males and females showed a significant decrease in feeding in the afternoon, relative to the morning, suggesting that these visual feeders forage less toward dusk and devote this time engaging in other behaviors. Consistent differences between morning and afternoon behaviors could additionally indicate that fish use cues from the environment such as light availability, angle or intensity to coordinate their behavior. In the case of feeding $N$. pulcher may also be using internal physiological cues (e.g. hunger) to regulate morning versus afternoon behaviors.

Pairs of male and female breeders were well matched in terms of gonadal investment suggesting that the monogamous breeding $N$. pulcher pairs sampled for this study were reproductively linked and possibly are using cues from the moon to activate and synchronize their reproductive axes. Male and female $N$. pulcher breeding pairs also showed an association in body size (mass and SL) with larger males mating with larger females. Several hypotheses exist to explain size-assortative mating (Crespi, 1989). (1) Size assortative mating may be the consequence or a biproduct of intra-sexual competition; if males compete intensely for territories with large females, only large competitive males will end up with large females; (2) size assortative mating may be a result of mate availability varying in relation to size so that only large males and females are abundant at one particular time and space; (3) mating constraints on mismatch may also lead to size assortative mating because large differences in body size could preclude reproduction; (4) mate choice, by either males, females or both with 
preferences for large body size will lead to size assortative mating as larger individuals out-compete smaller individuals for access to mates, leaving small individuals to mate only with other small individuals.

In the case of $N$. pulcher, the most plausible explanations for assortative mating are likely intra-sexual selection or mate choice. Small females are physically capable of mating with large males and vise versa (S. Balshine, pers. obs.) and significant variation exists in breeder body sizes across the spatial range of the study area used (Balshine, et al., 2001; Stiver, et al., 2008). Males may benefit from selecting large females if large females are more fecund (Savalli \& Fox, 1998) while females would benefit from selecting large males if large males are better able to provide care for young or protection from predators. Male and/or female mating preferences have never been documented in $N$. pulcher. However, in the field, when male breeding vacancies are created (Stiver, et al., 2006; Fitzpatrick, et al., 2008) the remaining female breeder defends her territory from incoming males (J. Desjardins, J. Fitzpatrick, K. Stiver, pers. obs.). Using this form of passive choice, a female may be able to defend her territory from smaller, less-suitable males while only large aggressive males are able to overcome her defensive tactics (Fitzpatrick et al., 2008).

In conclusion, the patterns presented here suggest that $N$. pulcher use cues from the moon to activate their reproductive axis and breed. We also document a strong diurnal behavioral pattern in $N$. pulcher (more feeding in the mornings), and within pair size matching and reproductive synchronicity within pairs.

\section{Acknowledgments}

This study was conducted with the permission of Dr H. Phiri, Dr Ngalada and Dr C. Kapasa of the Zambian Ministry of Agriculture, Food and Fisheries and the Government of Zambia. We are grateful to the staff of the Lake Tanganyika Research Unit for their great help and to D. Sinyinza, and R. Shapolla for their field assistance. In addition, we thank S. Marsh-Rollo for her comments on this MS. This study was also supported with funding from the Canada Foundation for Innovation and by the Natural Sciences and Engineering Research Council of Canada in the form of Discovery and Equipment grants to S.B. and G.V.D.K. and scholarships to J.K.D. and J.L.F. S.B. is supported by the Canada Research Chairs Program.

\section{References}

Aubin-Horth, N., Desjardins, J.K., Martei, Y.M., Balshine, S. \& Hofmann, H.A. (2007). Masculinized dominant females in a cooperatively breeding species. Mol. Ecol. 16, 1349-1358.

Balshine, S., Leach, B., Neat, F., Reid, H., Taborsky, M. \& Werner, N. (2001). Correlates of group size in a cooperatively breeding cichlid fish (Neolamprologus pulcher). Behav. Ecol. Sociobiol. 50, 134-140.
Balshine-Earn, S., Neat, F., Reid, H. \& Taborsky, M. (1998). Paying to stay or paying to breed? Field evidence for direct benefits of helping behavior in a cooperatively breeding fish. Behav. Ecol. 9, 432-438.

Brown, F.A. (1957). Biological chronometry. Am. Nat. 91, 129-133.

Bye, V.J. (1990). Temperate marine teleosts. Boca Raton: CRC Press.

Crespi, B.J. (1989). Causes of assortative mating in arthropods. Anim. Behav. 38, 980-1000.

Desjardins, J.K., Fitzpatrick, J.L., Stiver, K.A., Van Der Kraak, G.J. \& Balshine, S. (2008a). Costs and benefits of polygyny in the cichlid Neolamprologus pulcher. Anim. Behav. 75, 1771-1779.

Desjardins, J.K., Hazelden, M.R., Van Der Kraak, G.J. \& Balshine, S. (2006). Male and female cooperatively breeding fish provide support for the "Challenge Hypothesis". Behav. Ecol. 17, 149-154.

Desjardins, J.K., Stiver, K.A., Fitzpatrick, J.L., Milligan, N., Van Der Kraak, G.J. \& Balshine, S. (2008b). Sex and status in a cooperatively breeding fish: behavior and androgens. Behav. Ecol. Sociobiol. 62, 785-794.

Dierkes, P., Heg, D., Taborsky, M., Skubic, E. \& Achmann, R. (1998). Genetic relatedness in groups is sex specific and declines with age of helpers in a cooperatively breeding cichlid. Ecol. Lett. 8, 968-975.

Faulkes, C.G. \& Bennett, N.C. (2001). Family values: group dynamics and social control of reproduction in African mole-rats. Trends Ecol. Evol. 16, 184-190.

Faulkes, C.G., Trowell, S.N., Jarvis, J.U.M. \& Bennett, N.C. (1994). Investigation of numbers and motility of spermatozoa in reproductively active and socially suppressed males of two eusocial African mole-rats, the nake mole-rat (Heterocephalus glaber) and the Damaraland mole-rat (Cryptomys damarensis). J. Reprod. Fertil. 100, 411-416.

Findlay, C.S. \& Cooke, F. (1982). Synchrony in the lesser snow goose (Anser Caerulescens caerulescens). II. Adaptive value of reproductive synchrony. Evolution 66, 786-799.

Fitzpatrick, J.L., Desjardins, J.K., Milligan, N., Stiver, K.A., Montgomerie, R. \& Balshine, S. (2008). Female-mediated causes and consequences of status change in a social fish. Proc. Roy. Soc. Lond. Ser. B 275, 929-936.

Fitzpatrick, J.L., Desjardins, J.K., Stiver, K.A., Montgomerie, R. \& Balshine, S. (2006). Male reproductive suppression in the cooperatively breeding fish Neolamprologus pulcher, Behav. Ecology 17, 25-33.

Gochfeld, M. (1980). Mechanisms and adaptive value of reproductive synchrony in colonial seabirds. In Marine birds. Behavior of marine animals: current perspectives in research, 4: 207-270. Burger, J. et al. (Ed.). New York: Plenum Press.

Greeley, M.S., Marion, K.R. \& MacGregor, R. (1986). Semilunar spawning cycles of Fundulus similes (Cyprinodontidae). Env. Biol. Fish. 17, 79-83. 
Hau, M. (2001). Timing of breeding in variable environments: Tropical birds as model systems. Horm. Behav. 40, 281-290.

Heg, D., Bachar, Z. \& Taborsky, M. (2005). Cooperative breeding and group structure in the Lake Tanganyika cichlid, Neolamprologus savoryi. Ethology 11, 1017-1043.

Heg, D., Bergmuller, R., Bonfils, D., Otti, .O., Bachar, Z., Burri, R., Heckel, G. \& Taborsky, M. (2006). Cichlids do not adjust reproductive skew to the availability of independent breeding options. Behav. Ecol. 17, 419-429.

Helfman, G.S. (1993). Fish behaviour by day, night and twilight. In Behaviour of teleost fishes, 2nd edn: 285-305. Pitcher, T.J. (Ed.) New York: Chapman \& Hall.

Hoque, M.M., Takemura, A., Matsuyama, M., Matsuura, S. \& Takano, K. (1999). Lunar spawning in Siganus canaliculatus, . J. Fish. Biol. 55, 1213-1222.

Johannes, R.W. (1978). Reproductive strategies of coastal marine fishes in the tropics. Environ. Biol. Fishes 3, 65-84.

Kramer, D. (1978). Reproductive seasonality in the fishes of a tropical stream. Ecology 59, 976-985.

Lowe-McConnell, R.H. (1987). Ecological study in tropical fish communities. Cambridge: Cambridge University Press, Tropical Biology Series.

McMaster, M.E., Munkittrick, K.R., Jardine, J.J., Robinson, R.D. \& Van Der Kraak, G.J. (1995). Protocol for measuring in vitro steroid production by fish gonadal tissue. Can. Tech. Fish. Aquat. Sci. 1961, 1-18.

Miura, C., Takahashi, N., Michino, F. \& Miura, T. (2005). The effect of para-nonylphenol on Japanese eel (Anguilla japonica) spermatogenesis in vitro. Aquat. Toxicol. 71, 133-141.

Murphy, E.C. \& Schauer, J.H. (1996). Synchrony in egglaying and reproductive success of neighboring common mures, Uria Aalge, Behav. Ecol. Sociobiol. 39, 245-258.

Neat, F.C. \& Balshine-Earn, S. (1999). A field survey of the breeding habits of Eretmodus cyanostictus, a biparental mouthbrooding cichlid from lake Tanganyika. Environ. Biol. Fish. 55, 333-338.

Pankhurst, N.W. \& Carragher, J.F. (1991). Seasonal endocrine cycles in marine teleosts. In Reproductive physiology of fish: 131-135. Scott, A.P., Sumpter, J.P., Kime, D.E. \& Rolfe, M.S. (Eds) Sheffield: FishSymp 91.

Rahman, M.S., Morita, M. \& Takemura, A. (2003). Hormonal changes in relation to lunar periodicity in the testis of the forktail rabbitfish, Siganus argenteus. Gen. Comp. Endocrinol. 131, 302-309.

Richardson, D.S., Jury, F.L., Blaakmeer, K., Komdeur, J. \& Burke, T. (2001). Parentage assignment and extr-group paternity in a cooperative breeder: the Seychelles warbler (Acrocephalus sechellensis). Mol. Ecol. 10, 2263-2273.

Rosenthal, R. \& Rosnow, R.L. (1985). Statistical procedures and the justification of knowledge in psychological science. Cambridge: Cambridge University Press.
Rossiter, A. (1991). Lunar spawning synchroneity in a freshwater fish. Naturwissenschaften 78, 182-184.

Savalli, U.M. \& Fox, C.W. (1998). Sexual selection and the fitness consequences of male body size in the seed beetle Stator limbatus. Anim. Behav. 55, 473-483.

Schwanck, E. (1987). Lunar periodicity in the spawning of Tilapia mariae in the Ethiope River, Nigeria. J. Fish Biol. 30, 533-537.

Smith, H.G. (2004). Selection for synchronous breeding in the European starling. Oikos 105, 301-311.

Sopinka, N.M., Fitzpatrick, J.L., Desjardins, J.K., Stiver, K.A., Marsh-Rollo, S.E. \& Balshine, S. (2009). Liver size as an indicator of social status in an African cichlid fish. J. Fish Biol. 75, 1-16.

Stiver, K.A., Desjardins, J.K., Fitzpatrick, J.L., Neff, B., Quinn, J.S. \& Balshine, S. (2007). Evidence for size and sexspecific dispersal in a cooperatively breeding cichlid. Mol. Ecol. 16, 2974-2984.

Stiver, K.A., Dierkes, P., Taborsky, M. \& Balshine, S. (2004). Dispersal patterns and status change in a co-operatively breeding cichlid Neolamprologus pulcher: evidence from microsatellite analyses and behavioural observations. J. Fish Biol. 65, 91-105.

Stiver, K.A., Dierkes, P., Taborsky, M., Gibbs, H.L. \& Balshine, S. (2005). Relatedness and helping in fish: examining the theoretical predictions. Proc. Roy. Soc. Lond. Ser. B 272, 1593-1599.

Stiver, K.A., Fitzpatrick, J.L., Desjardins, J.K. \& Balshine, S. (2006). Sex difference in territory joining and inheritance in a cooperatively breeding cichlid fish. Anim. Behav. 71, 449-456.

Stiver, K.A., Fitzpatrick, J.L, Desjardins, J.K., Neff, B.D., Quinn, J.S. \& Balshine, S. (2008). The role of genetic relatedness among social mates in a cooperative breeder. Behav. Ecol. 73, 1025-1028.

Stiver, K.A., Fitzpatrick, J.L., Desjardins, J.K. \& Balshine, S. (2009). Mixed parentage in Neolamprologus pulcher groups. J. Fish Biol. 74, 1129-1135.

Taborsky, M. (1984). Broodcare helpers in the cichlid fish Lamprologus brichardi: their costs and benefits. Anim. Behav. 32, 1236-1252.

Taborsky, M. \& Limberger, D. (1981). Helpers in Fish. Behav. Ecol. Sociobiol. 8, 143-145.

Takemura, A. \& Rahman, M.S. (2004). Lunar cycles and reproductive activity in reef fishes with particular attention to rabbitfishes. Fish Fish. 5, 317-328.

Trivers, R. (1985). Social evolution. Menlo Park: Benjamin/ Cummins Publishing Co.

Watanabe, T. (2000). Lunar cyclid spawning of a mouthbrooding cichlid, Cyprichromis leptosoma, in Lake Tanganyika. Ichthyol. Res. 47, 307-310. 